\title{
Phosphorus implantation of Mg-doped (AI)GaN heterostructures: structural examination and depth profiling
}

\author{
Karolina Piętak ${ }^{1,2, *}$ (D), Sebastian Złotnik ${ }^{1,4}$ (D), Ewelina Rozbiegała ${ }^{1,3}$ (D), Paweł P. Michałowski ${ }^{1}$ (D), \\ Marek Wójcik ${ }^{1}$, Jarosław Gaca ${ }^{1}$, and Mariusz Rudziński ${ }^{1}$ \\ ${ }^{1}$ Łukasiewicz Research Network - Institute of Electronic Materials Technology, Wólczyńska 133, 01-919 Warsaw, Poland \\ ${ }^{2}$ Faculty of Chemistry, Warsaw University of Technology, Noakowskiego 3, 00-664 Warsaw, Poland \\ ${ }^{3}$ Faculty of Materials Science and Engineering, Warsaw University of Technology, Wołoska 141, 02-507 Warsaw, Poland \\ ${ }^{4}$ Present address: Institute of Applied Physics, Military University of Technology, Kaliskiego 2, 00-908 Warsaw, Poland
}

Received: 30 April 2020

Accepted: 25 August 2020

Published online:

17 September 2020

(C) The Author(s) 2020

\begin{abstract}
Phosphorus introduction into Mg-doped aluminium gallium nitride ((Al)GaN) epilayers to enhance the acceptor activation is a possible strategy for a p-type conductivity improvement in III-nitride wide-bandgap semiconductors. To date, P-implanted Mg-doped (Al)GaN structures have not been systematically evaluated, regarding structural verification and elemental distribution. Here, comprehensive studies of $\mathrm{P}$ ions impact on structural degradation are presented. Furthermore, a post-implantation annealing conducted at different temperatures is examined as well. The results demonstrated that the structural changes in the examined compounds, namely $\mathrm{GaN}$ and $\mathrm{Al}_{0.1} \mathrm{Ga}_{0.9} \mathrm{~N}$, due to $\mathrm{P}$ implantation and a subsequent recovery by thermal annealing follow similar trends. Interestingly, it was revealed that $\mathrm{P}$ diffusion length is higher in AlGaN than in $\mathrm{GaN}$, possibly due to higher oxygen content in Al-containing compounds, analogous to $\mathrm{Mg}$ dopant. Additionally, the initial $\mathrm{Mg}$ concentration in (Al)GaN is crucial because too high $\mathrm{Mg}$ doping could be the main cause of electrical properties degradation of (Al) GaN heterostructures after P ion implantation.
\end{abstract}

\section{Introduction}

Gallium nitride (GaN)-based materials with a direct bandgap are widely used in optoelectronic and electronic devices such as light-emitting diodes, high power, and speed transistors [1]. In these compositions, it is important to obtain a material with a particular conductivity type. N-type doping of aluminium gallium nitride ( $\mathrm{AlGaN})$ is rather well established and controlled [2], while achieving a

Karolina Piętak and Sebastian Złotnik contributed equally to this work.

Address correspondence to E-mail: karolina.pietak@itme.edu.pl 
p-type AlGaN with good electrical parameters remains a challenge.

Ion implantation is one of the methods to introduce the additives to the structure. Basically, it consists two stages: (i) the ion beam bombardment of a layer with a high enough specific energy (more than $50 \mathrm{keV}$ ) and (ii) post-process heating. Depending on the dopants that are introduced into the GaN-based structure, there may be different effects, mainly changes in electrical and optical parameters. For example, GaN implanted with zinc or oxygen ions possesses better luminescence characteristics compared to undoped GaN [3]. Besides, silicon implantation in the GaN structure results in a lower resistance [4]. The opposite results are observed while $\mathrm{GaN}$ is implanted with helium and nitrogenthese atoms are used to produce resistive material [4].

An additional possibility offered by implantation is the ability to obtain p-type conductivity in AlGaN heterostructures by introducing acceptor dopants such as magnesium or oxygen [5]. $\mathrm{Mg}$ is the most frequently used element to obtain a p-type conductivity [6], but its concentration in AlGaN structures is still too low. This issue is related to the large ionization energy of $\mathrm{Mg}$ acceptor, which limits the number of holes in AlGaN structure [7-9]. Post-implantation annealing is one of the problems that also appear during ion implantation processes in $\mathrm{GaN}-$ based heterostructures. Zolper et al. presented that the optimal activation temperature for $\mathrm{GaN}$ is $1700{ }^{\circ} \mathrm{C}$ [10]. However, GaN begins to degrade already at $1000{ }^{\circ} \mathrm{C}$, and according to Karpinski's research, the decomposition half-life of $\mathrm{GaN}$ at $1100{ }^{\circ} \mathrm{C}$ is $20000 \mathrm{~s}[11,12]$. For this reason, various derivatives of post-implantation heating are developed, limiting the possibility of GaN degradation, such as: Rapid Thermal Annealing (RTA) [13], multicycle RTA [14, 15], Laser Thermal Annealing (LTA) [5], or microwave annealing [16].

Furthermore, it was reported that the Mg implantation into $\mathrm{GaN}$ produces large number of nitrogen vacancies, which are very difficult to remove by postimplantation annealing. To improve efficiently $\mathrm{Mg}$ doping in III-N structures, Pearton et al. suggested the use of the co-implantation of $\mathrm{Mg}$ and phosphorus ions simultaneously [4]. The authors showed that the implanting elements from the group $\mathrm{V}$ (such as $\mathrm{P}$ ) could effectively improve conductivity of p-type GaN (with comparison to single impurity doping) [4]. It was stated that the main reason of such improvement is due to the reduction of $\mathrm{N}$ vacancies and the $\mathrm{Mg}$ substitution by the incorporation of $\mathrm{P}$ atom [8].

Polyakov et al. studied the co-implantation of $\mathrm{Mg} /$ $P$ ions in $\mathrm{AlGaN}$ heterostructures [17]. In their research, for post-implantation annealing, they used ammonia and in the next step nitrogen as an atmosphere during heating. The dwell time of these treatments was also quite long $(1 \mathrm{~h})$ with comparison to other works where the time of annealing was usually several minutes [17]. The only reports on ion implantation in Mg-doped AlGaN appear in Frazier et al. [18] and Polyakov et al. [19] works, where transition metal ions (such as: $\mathrm{Mn}, \mathrm{Cr}$, or $\mathrm{Co}$ ) were implanted. On the other hand, doping through implantation of various ions: oxygen [20], silicon [21-24] into the AlGaN structure was demonstrated to obtain n-type conductivity.

In this work, the structural analysis and depth profiling of P-implanted Mg-doped (Al)GaN heterostructures grown epitaxially were studied. P ions implantation took place at the dose of $5 \times 10^{14} \mathrm{~cm}^{-2}$ and hence post-implantation annealing effects were examined. The samples were characterized by: High-Resolution X-Ray Diffraction (HRXRD), Raman Spectroscopy and Secondary Ion Mass Spectroscopy (SIMS), in order to trace structural changes and examine depth elemental distribution of $\mathrm{Mg}$ dopant and implanted $\mathrm{P}$ ions.

\section{Experimental section}

\subsection{Epitaxial growth and implantation}

Mg-doped $\mathrm{GaN}$ and $\mathrm{Al}_{0.1} \mathrm{Ga}_{0.9} \mathrm{~N}$ epitaxial structures were grown on 2-inch single side polished sapphire $\left(\mathrm{Al}_{2} \mathrm{O}_{3}\right)$ substrates (maximum off-cut $\left.\pm 0.25^{\circ}\right)$. The growth of the structures was conducted in low pressure metalorganic vapour phase epitaxy reactor (LP MOVPE) - AIX 200/4 RF-S. In the processes, the consecutive precursors were used: trimethylaluminium (TMAl), trimethylgallium (TMGa), ammonia $\left(\mathrm{NH}_{3}\right)$ and bis-cyclopentadienylmagnesium $\left(\mathrm{Cp}_{2} \mathrm{Mg}\right)$; hydrogen $\left(\mathrm{H}_{2}\right)$ and nitrogen $\left(\mathrm{N}_{2}\right)$ were used as the carrier gases. In the MOVPE system a temperature was in situ controlled by emissivity corrected pyrometry using a Laytec EpiCurve TT system.

$\mathrm{Mg}$-doped (Al)GaN structures were grown on AlN/sapphire template at $1000{ }^{\circ} \mathrm{C}$ and 200 mbar. To activate the $\mathrm{Mg}$ dopant, the last stage of the epitaxy 
process was post-growth annealing in nitrogen at a temperature of $800{ }^{\circ} \mathrm{C}$ for $30 \mathrm{~min}$. As a result of the performed processes, the following epitaxial structures were further processed: (Al)GaN:Mg ( $200 \mathrm{~nm}$ )/AlN ( $850 \mathrm{~nm}$ thick)/sapphire substrate. The obtained heterostructures were cut into $10 \times 10 \mathrm{~mm}$ pieces, one of which was left as a reference sample, while the remaining part was used to study the effect of $P$ implantation.

The P implantation process was carried out at room temperature with energy equal to $150 \mathrm{keV}$. The dose of implanted ions was the same for both implanted structures-5 $510^{14} \mathrm{~cm}^{-2}$. The scheme presenting the P implantation of $(\mathrm{Al}) \mathrm{GaN}: \mathrm{Mg}$ is shown in Fig. 1.

After the implantation, the structures were annealed by conventional RTA at different temperatures $\left(900,1000\right.$, and $1100{ }^{\circ} \mathrm{C}$ ) for $3 \mathrm{~min}$, in $\mathrm{N}_{2}$ gas atmosphere.

\subsection{Characterization}

Structural studies were carried out using high-resolution X-ray diffraction (HR-XRD). For this purpose the SmartLab diffractometer equipped with a $9 \mathrm{~kW}$ rotating $\mathrm{Cu}$ anode (wavelength $\mathrm{CuK \alpha 1}$ equals $0.15405 \mathrm{~nm}$ ) was used. The symmetric $2 \theta / \omega$ diffraction profiles were recorded for the following incident optics setting: cross-beam optics $\mathrm{CBO}$ unit, $\mathrm{Ge}(220) \times 2$ monochromator, open soller slit, and on the receiving side: an open soller slit and soller slit $5.0^{\circ}$. All measured samples were adjusted in such a way that the $c$-axis was parallel to the $\theta$-axis of the goniometer. This allows to carry on the radial scans of the (0002) reciprocal lattice spot of AlGaN as well as AlN monocrystals.

Raman measurements were carried out using a Renishaw inVia Reflex spectrometer. The measurements were conducted at room temperature at normal conditions. The Raman spectra were collected in backscattering geometry using the $532 \mathrm{~nm}$ second harmonic of an Nd:YAG laser. The laser beam was focused through the objective $100 \times$ to the spot about $0.6 \mu \mathrm{m}$ in diameter with an average laser power of 5 $\mathrm{mW}$.

SIMS measurements were performed employing the CAMECA SC Ultra instrument under ultra-high vacuum (UHV), usually of $4 \times 10^{-10} \mathrm{mbar}$. $\mathrm{Cs}^{+}$primary beam scanned over $100 \times 100 \mu \mathrm{m}^{2}$ was used in the experiment while the analysis area was limited to $50 \times 50 \mu \mathrm{m}$. Impact energy was $2 \mathrm{keV}$ whereas primary beam current was $20 \mathrm{nA}$. Negative and positive polarity was used to detect phosphorus and magnesium ions, respectively.

The electrical properties were determined by Hall effect measurements, using van der Pauw geometry (Ecopia HMS-3000 setup) on $10 \times 10 \mathrm{~mm}$ samples at $0.55 \mathrm{~T}$ magnetic field. At least 3 measurements were done for each sample to obtain statistical data.

\section{Results and discussion}

\subsection{Structural examination}

XRD measurements were performed to examine structural changes in the as-grown, P-implanted and post-implantation annealed at 900,1000 , and $1100{ }^{\circ} \mathrm{C}$ (Al) GaN:Mg structures. Figure 2 depicts diffraction profiles corresponding to near (0002) (Al)GaN and AlN (shown solely for the as-grown structures) peaks and collected at a range of $33^{\circ}-38^{\circ} 2 \theta / \omega$. Interplanar spacings $\left(d_{0002}\right)$ were determined by the measurement of the centre of gravity (0002) (Al)GaN reflection for the reference as well as implanted/annealed structures. It can be clearly seen that the interplanar spacing between (0002) lattice planes of $\mathrm{GaN}: \mathrm{Mg}$

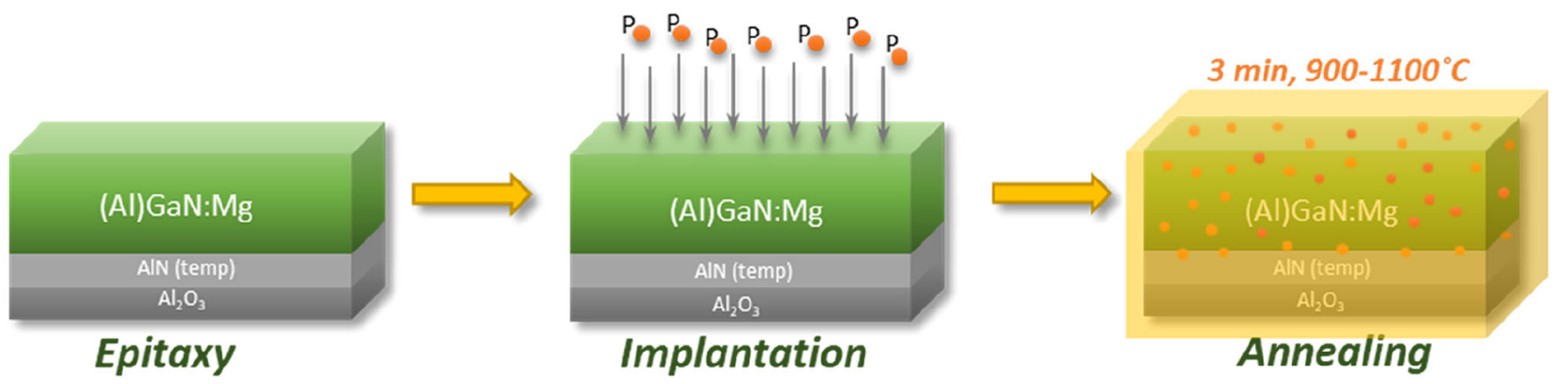

Fig. 1 Scheme of examined Mg-doped ( $\mathrm{Al}) \mathrm{GaN}$ heterostructures (epitaxy), P ions implantation and further annealing 


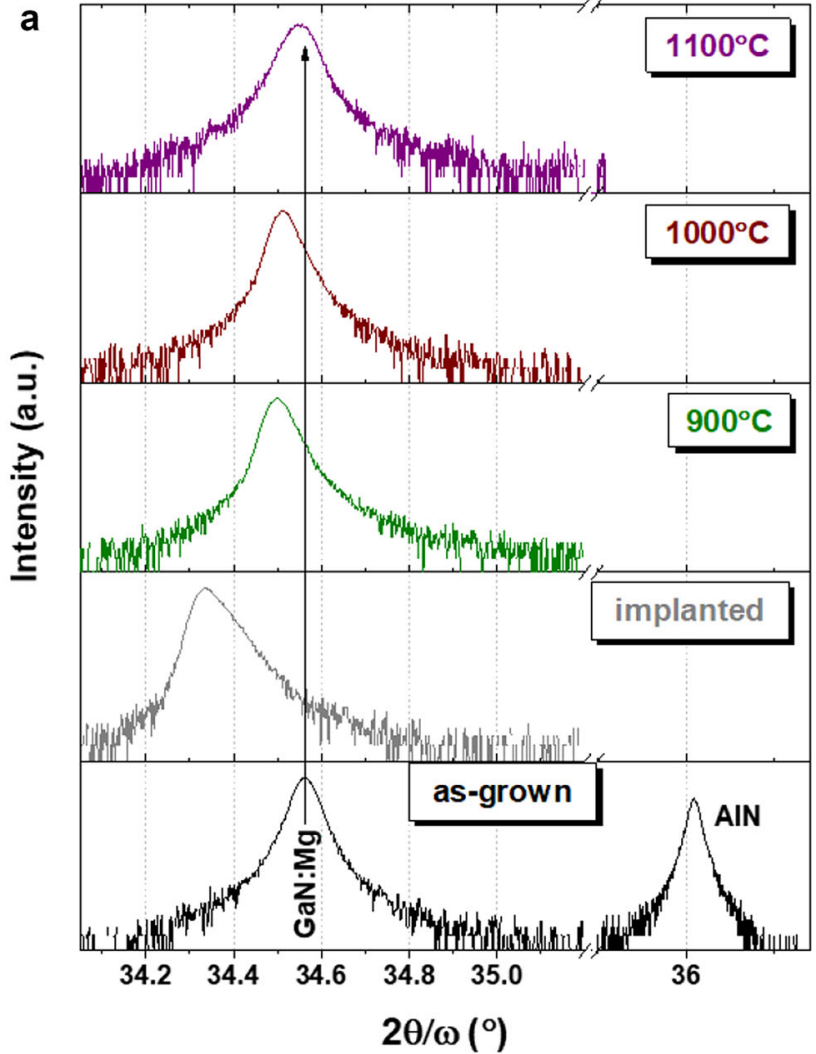

Fig. 2 X-ray diffraction profiles of the as-grown, P-implanted and annealed at 900, 1000, and $1100{ }^{\circ} \mathrm{C} \mathrm{Mg-doped} \mathrm{GaN}$ (a) and $\mathrm{AlGaN}$ (b) heterostructures. XRD diffraction profiles were collected at a range of $33^{\circ}-38^{\circ}(2 \theta / \omega)$ to record (0002) (Al)GaN reflections and AIN template as well. (0002) AlN is presented

$\left(34.55^{\circ}\right)$ increases after $\mathrm{P}$ ions implantation and further annealing process partially restores the wurtzite structure arrangement to the state prior to implantation; similar behaviour is observed in the case of AlGaN:Mg structure (Fig. 2b). It means that because of $\mathrm{P}$ ion implantation, the unit cell of $\mathrm{GaN}$ and AlGaN expands in the $c$ directions (visible as the shift of the (0002) (Al)GaN diffraction lines towards lower $2 \theta / \omega$ angles). The post-implantation annealing at an appropriate temperature regenerates the structure and makes the angular position of the (Al)GaN (0002) reflections practically to the state of their respective the as-grown structures. Moreover, some structural changes occur in AlN underlayer of P-implanted AlGaN:Mg, observed as a shoulder in Fig. $2 \mathrm{~b}$ around $36^{\circ}$. Thus, it suggests that the implanted ions diffused through the entire $\mathrm{AlGaN}: \mathrm{Mg}$ layer and they were partially located in the AlN.

Furthermore, to trace the structural changes between the as-grown and the implanted, and then

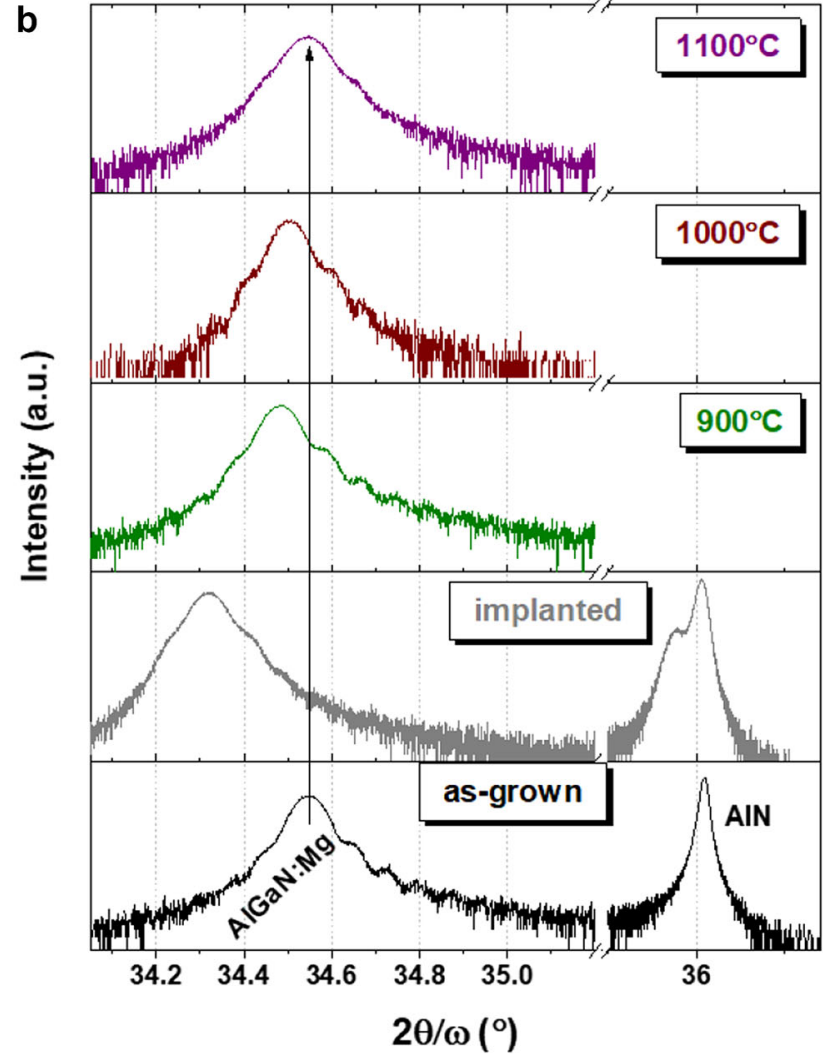

solely for the as-grown (Al)GaN structures at $2 \theta / \omega=36.05^{\circ}$, and in addition for P-implanted AlGaN because it was observed that $\mathrm{P}$ diffused through AlGaN to underlying AlN (a shoulder from the left)

annealed (Al)GaN:Mg structures, lattice mismatch $\left(\Delta d_{0002} / d_{0002}\right)$ and full width at half maximum (FWHM) broadening $\left(B_{\mathrm{FWHM}}\right)$ factor were determined from profile fitting (see Table 1); the relationships are included in the Electronic Supplementary Material.

The relative changes in the (0002) interplanar distances of implanted and annealed GaN:Mg and AlGaN:Mg layers in relation to $d_{0002}$ of the as-grown structures indicate that as the annealing temperature increases, the structure recovers to its initial stage. Ion implantation process expands $\mathrm{GaN}: \mathrm{Mg}$ and AlGaN:Mg lattice by 0.55 and $0.59 \%$, respectively, and their structure contract back to almost initial stage (as-grown): 0.03 and $0.01 \%$ lattice mismatch of GaN:Mg and AlGaN:Mg, respectively, annealed at $1100{ }^{\circ} \mathrm{C}$. The obtained results indicate that both $\mathrm{GaN}: \mathrm{Mg}$ and AlGaN:Mg layers are similarly susceptible to implantation of $\mathrm{P}$ ions. 
Table 1 Structural mismatch and broadening factor $\left(B_{\mathrm{FWHM}}\right)$ derived from HR-XRD of the as-grown, P-implanted and annealed at distinct temperatures $\mathrm{Mg}$-doped (Al)GaN structures

\begin{tabular}{|c|c|c|c|c|}
\hline & \multicolumn{2}{|l|}{ GaN:Mg } & \multicolumn{2}{|l|}{$\mathrm{Al}_{0.1} \mathrm{Ga}_{0.9} \mathrm{~N}: \mathrm{Mg}$} \\
\hline & $\begin{array}{l}\text { Lattice mismatch } \\
{\left[2 \theta / \omega\left(^{\circ}\right)\right]}\end{array}$ & $\begin{array}{l}B_{\mathrm{FWHM}} \\
{[\mathrm{FWHM}(\operatorname{arcsec})]}\end{array}$ & $\begin{array}{l}\text { Lattice mismatch } \\
{\left[2 \theta / \omega\left(^{\circ}\right)\right]}\end{array}$ & $\begin{array}{l}B_{\mathrm{FWHM}} \\
{[\mathrm{FWHM}(\operatorname{arcsec})]}\end{array}$ \\
\hline As-grown & $\begin{array}{l}0 \% \\
(34.559 \pm 0.0005)\end{array}$ & $\begin{array}{l}0 \% \\
(177.5 \pm 1.1)\end{array}$ & $\begin{array}{l}0 \% \\
(34.5489 \pm 0.0002)\end{array}$ & $\begin{array}{l}0 \% \\
(257.8 \pm 0.7)\end{array}$ \\
\hline Implanted & $\begin{array}{l}0.55 \% \\
(34.312 \pm 0.0008)\end{array}$ & $\begin{array}{l}31.5 \% \\
(249.1 \pm 2.5)\end{array}$ & $\begin{array}{l}0.59 \% \\
(34.3180 \pm 0.0001)\end{array}$ & $\begin{array}{l}40.7 \% \\
(315.7 \pm 0.7)\end{array}$ \\
\hline Ann. @ $9000^{\circ} \mathrm{C}$ & $\begin{array}{c}0.15 \% \\
(34.5006 \pm 0.0003)\end{array}$ & $\begin{array}{l}10.2 \% \\
(200.9 \pm 0.7)\end{array}$ & $\begin{array}{l}0.17 \% \\
(34.4830 \pm 0.0002)\end{array}$ & $\begin{array}{l}14.5 \% \\
(278.3 \pm 0.7)\end{array}$ \\
\hline Ann. @1000 ${ }^{\circ} \mathrm{C}$ & $\begin{array}{l}0.12 \% \\
(34.5127 \pm 0.0003)\end{array}$ & $\begin{array}{l}3.6 \% \\
(185.7 \pm 0.7)\end{array}$ & $\begin{array}{l}0.11 \% \\
(34.5037 \pm 0.0004)\end{array}$ & $\begin{array}{l}5.1 \% \\
(265.0 \pm 1.4)\end{array}$ \\
\hline Ann. @ $1100{ }^{\circ} \mathrm{C}$ & $\begin{array}{l}0.03 \% \\
(34.5460 \pm 0.0004)\end{array}$ & $\begin{array}{l}38.9 \% \\
(266.0 \pm 1.0)\end{array}$ & $\begin{array}{l}0.01 \% \\
(34.5436 \pm 0.0003)\end{array}$ & $\begin{array}{l}57.4 \% \\
(339.5 \pm 1.0)\end{array}$ \\
\hline
\end{tabular}

$B_{F W H M}$ FWHM broadening factor (\%), FWHM full width at half maximum

The second parameter is associated with a FWHM broadening $\left(B_{\mathrm{FWHM}}\right)$, calculated in respect to $\mathrm{AlN}$ template of the as-grown ( $\mathrm{Al}) \mathrm{GaN}: \mathrm{Mg}\left(\mathrm{FWHM}_{\mathrm{AlN}}\right.$ is equal to $0.0633 \pm 0.0001^{\circ}$ or $0.0396 \pm 0.0004^{\circ}$ in the case of $\mathrm{GaN}: \mathrm{Mg}$ or $\mathrm{AlGaN}: \mathrm{Mg}$, respectively), which is related to implantation-induced damages resulting in the expansion of the $(\mathrm{Al}) \mathrm{GaN}$ hexagonal lattice. It is worth mentioning that an energetic ion penetrating through the (Al)GaN:Mg layer generates a collision cascade, which consists of vacancies and interstitials. After ion implantation, the $B_{F W H M}$ increases significantly, being around $31 \%$ for P-implanted GaN:Mg and around $41 \%$ for P-implanted AlGaN:Mg, together with the peak shift to the left being an indication of a tensile elastic strain along the [0001] direction [25]. This effect results from elastic lattice distortions induced by intercalation of the implanted $\mathrm{P}$ and matrix atoms ( $\mathrm{Ga}, \mathrm{Al}, \mathrm{Mg}$ or $\mathrm{N})$ knocked off lattice sites by the high energy ion beam during implantation. As the annealing temperature increases (up to $1000{ }^{\circ} \mathrm{C}$ ), the $B_{\text {FWHM }}$ decreases, which therefore means that implantation- induced elastic strain was at least partially relieved after thermal treatment at 900 and $1000{ }^{\circ} \mathrm{C}$.

Additionally, the temperature of regeneration is also a key aspect during post-implantation annealing. Even though the lattice mismatch of the structure annealed at $1100{ }^{\circ} \mathrm{C}$ is the smallest for both $\mathrm{GaN}: \mathrm{Mg}$ and AlGaN:Mg, the $B_{F W H M}$ factor for these structures is higher than just after P implantation. It indicates a severe structural degradation, coinciding well with the results obtained by Karpinski, which showed that $\mathrm{GaN}$ begins to degrade while annealed at temperatures higher than $1000{ }^{\circ} \mathrm{C}$ [11]. Therefore it is obvious that ion implantation solely causes significant structural changes-both the FWHM and the distance between planes increases. This is in a contrary to Sumiya et al. studies where it was found that FWHM does not depend on the annealing [26].

The structural modifications induced by $\mathrm{P}$ implantation and subsequent annealing at distinct temperatures were investigated by Raman spectroscopy as well. Figure 3 shows Raman spectra in a wavenumber range of $280-820 \mathrm{~cm}^{-1}$ of $\mathrm{GaN}: \mathrm{Mg}$ (a) and $\mathrm{AlGaN}: \mathrm{Mg}$ (b) heterostructures recorded at room temperature and using green laser excitation; each graph is divided into three distinct frames: (i) the as-grown (bottom), (ii) P-implanted (middle), and (iii) annealed (top) structures. The Raman spectra are composed of characteristic peaks assigned not only to (Al)GaN:Mg layers but also to AlN underlayer $\left(610,660\right.$, and $\left.670 \mathrm{~cm}^{-1}\right)$ [27] and sapphire substrate $\left(370-450,575,640\right.$, and $\left.750 \mathrm{~cm}^{-1}\right)$ [28] because the penetration of the used laser is few microns in depth. The positions of (Al)GaN peaks observed at frequency positions around 570 and $735 \mathrm{~cm}^{-1}$ correspond to $E_{2}$ (high) and $A_{1}$ (LO) modes, respectively, marked in the bottom frame presenting the as-grown ( $\mathrm{Al}) \mathrm{GaN}: \mathrm{Mg}$ spectra.

The Raman spectra of P-implanted structures are very noisy with high background intensity. The increase of background intensity, in particular at low 

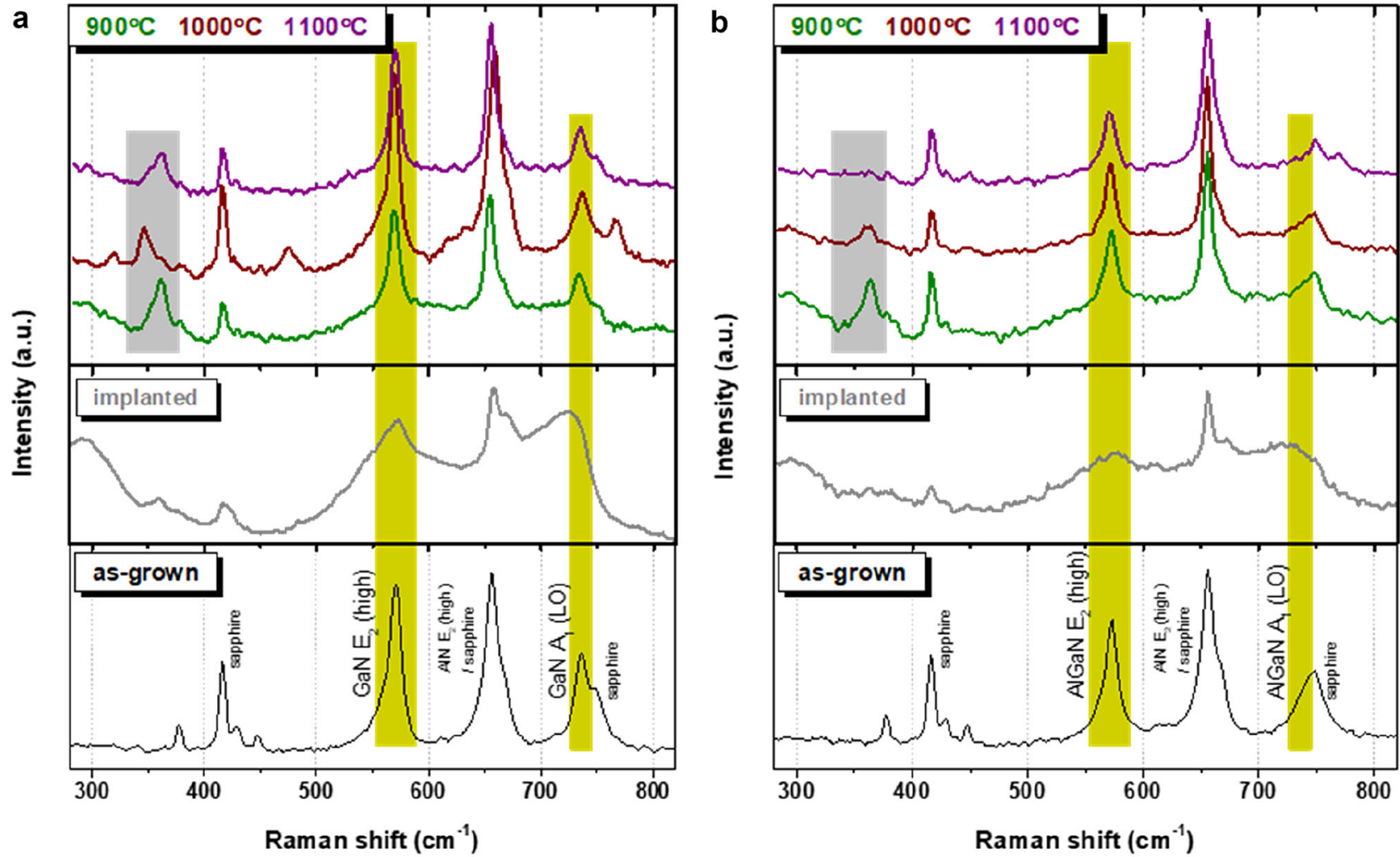

Fig. 3 Raman spectra of the as-grown (bottom), P-implanted (middle) and annealed (top) GaN:Mg (a) and AlGaN:Mg (b) using a $532 \mathrm{~nm}$ laser. Changes of (Al)GaN $E_{2}$ (high) and $A_{1}(\mathrm{LO})$ modes are marked

frequencies, can be attributed to the second-order Raman processes activated due to the implantationinduced disorders and involving the combination of acoustic and optic phonon modes $[29,30]$ or due to the increased Rayleigh scattering caused by defect enhancement [31]. Moreover, the absence of any resolvable Raman modes of $(\mathrm{Al}) \mathrm{GaN}$ is an indication that the solely implanted (Al)GaN:Mg layers are highly defective or even partially amorphous due to implantation damage. Apart from aforementioned observations in P-implanted Raman spectra, there are additional broad peaks appearing on the spectra of implanted samples: (i) around $300 \mathrm{~cm}^{-1}$, (ii) around $360 \mathrm{~cm}^{-1}$, (iii) around $420 \mathrm{~cm}^{-1}$ (overlapped with peaks originating from sapphire substrate), and (iv) around $675 \mathrm{~cm}^{-1}$. All these peaks can be categorized into disorder activated Raman scattering (DARS) and scattering mechanisms of implantation-induced defects, namely interstitials, vacancies $\left(V_{\mathrm{N}}, V_{\mathrm{Ga} / \mathrm{Al}}\right)$ or antisites in the host lattice. The specific nature of the defects that give rise to the appearing of post-implanted peaks was well discussed by Katiskini et al. [31] and recently by Pandey et al. [30] in various ion- implanted GaN, mainly with oxygen, nitrogen, magnesium, and silicon. Similarly, other studies of ion-implanted $\mathrm{GaN}$ with rare-earth metals (Er, Gd) $[32,33]$ or other elements $(\mathrm{Be}, \mathrm{C})[34,35]$ were reported discussing different multiphonon behaviour. It is worthwhile to mention that the intensity ratio of $E_{2}$ (high) to $A_{1}$ (LO) changes, besides their line broadening (FWHM). $A_{1}$ (LO) intensity increases comparing to the as-grown ( $\mathrm{Al}) \mathrm{GaN}: \mathrm{Mg}$, being an indication of free carrier concentration decrease due to a reduced screening of phonons by charge carriers $[29,30]$.

The post-implantation annealing is normally necessary to activate the implanted ions and recover the structure to the state prior to implantation. It is obviously evident in Raman spectra of post-implantation annealed at 900, 1000 , and $1100{ }^{\circ} \mathrm{C}$ (Al)GaN:Mg structures (see Fig. 3, top frame) that the wurtzite crystalline quality is improved with thermal annealing, indicated by an appearance of clear, sharp and able to be resolved $E_{2}$ (high) mode. Despite an employed heat treatment for structural recovery, some of the implantation-induced Raman peaks do 
not disappear, mainly the one around $360 \mathrm{~cm}^{-1}$. Furthermore, post-implantation annealing gives rise to new modes which may arise from P-related local vibration modes, being an indication that the implanted ions occupy substitutional sites.

Moreover, a detailed quantitative analysis was carried out, devoted to $E_{2}$ (high) peak interpretation. Therefore, the Raman spectra were carefully analysed by fitting Raman active $E_{2}$ (high) using a pseudoVoigt function, and further the relative biaxial stress $\left(\sigma_{\mathrm{a}}\right)$ was calculated from the shear-lag model [36]; it is precisely described in the Electronic Supplementary Material. Deconvoluted data of Raman shift (wavenumber $\omega_{\mathrm{E} 2}$ ), $\mathrm{FWHM}_{\mathrm{E} 2}$ and determined biaxial stress in respect to the as-grown ( $\mathrm{Al}) \mathrm{GaN}: \mathrm{Mg}$ structures are shown in Table 2. It is known that $E_{2}$ (high) is sensitive to the crystal structure imperfection (peak height and width change) and strain (frequency position change). The red phonon frequency shift of $\omega_{\mathrm{E} 2}$ for the as-grown AlGaN:Mg compared to $\mathrm{GaN}: \mathrm{Mg}$ is related to an increase of $\mathrm{Al}$ content in AlGaN alloy. There is an evident blue shift (to lower frequencies) of $\omega_{\mathrm{E} 2}$ within the same (Al)GaN composition while post-implantation annealing was conducted. It is probably associated with compressive or tensile strain due to the difference in ionic radii between host atoms $(\mathrm{Ga}, \mathrm{Al}, \mathrm{N})$ and $\mathrm{P}$ atom. The $\sigma_{\mathrm{a}}$ decreases with annealing temperature for implanted GaN:Mg and increases for implanted AlGaN:Mg. This behaviour can be related to a compositional change in AlGaN.

\subsection{Elemental depth profiling}

SIMS measurements were performed to trace $\mathrm{Mg}$ and $\mathrm{P}$ changes in post-implanted and annealed Mg-doped (Al)GaN structures. Figure 4 presents elemental depth profiles for the as-grown, P-implanted and annealed at $1000{ }^{\circ} \mathrm{C}$ (Al)GaN:Mg; $\mathrm{Mg}$ and $\mathrm{P}$ profiles were normalized to the adequate references. Similarly to our previous studies on $\mathrm{Mg}$ diffusion in (Al)GaN compounds [6, 38], the $\mathrm{Mg}$ concentration gradually increases towards the surface, reaching $>10^{19} \mathrm{~cm}^{-3}$, independently on implantation and annealing conditions. Thus, it can be stated that during $\mathrm{P}$ implantation, the $\mathrm{Mg}$ ions do not diffuse across the structures. After post-implantation annealing $\mathrm{Mg}$ profiles change a bit dependently on the composition: (i) in GaN the Mg diffuses towards surface (near surface region of about $20 \%$ of total layer thickness), and (ii) in AlGaN the $\mathrm{Mg}$ diffuses deeper into AlN template. This behaviour can be associated to the higher content of oxygen in $\mathrm{Al}_{0.1} \mathrm{Ga}_{0.9} \mathrm{~N}$ (approximately $2 \times 10^{17} \mathrm{~cm}^{-3}$ ) than in GaN (less than $5 \times 10^{16} \mathrm{~cm}^{-3}$ ), facilitating $\mathrm{Mg}$ transport through the crystal lattice, how it was described in our previous work [6].

Furthermore, an interesting is the elemental distributions of $\mathrm{P}$ ions in ( $\mathrm{Al}) \mathrm{GaN}: \mathrm{Mg}$ heterostructures. In $\mathrm{GaN}: \mathrm{Mg}$ and $\mathrm{Al}_{0.1} \mathrm{Ga}_{0.9} \mathrm{~N}: \mathrm{Mg}$, the phosphorus concentration reaches $>10^{19} \mathrm{~cm}^{-3}$, at the $25 \%$ and $100 \%$ of the layer thickness, for GaN:Mg and AlGaN:Mg, respectively. Additionally, it can be seen for AlGaN:Mg that $\mathrm{P}$ ions diffuse deep into underlying AlN, similarly to $\mathrm{Mg}$ distribution but at higher extent, more than $150 \%$ of total AlGaN:Mg layer thickness. Thus, it is crucial to point out here that due to the high implantation energy and dose (similar for both structures), the P ions are distributed not only in the Mg-doped layer, but also the AlN buffer layer.

Table 2 Deconvoluted Raman spectra of $E_{2}$ (high) mode with calculated relative biaxial stress (according to [36, 37])

\begin{tabular}{|c|c|c|c|c|c|c|}
\hline & \multicolumn{3}{|l|}{ GaN:Mg } & \multicolumn{3}{|l|}{$\mathrm{Al}_{0.1} \mathrm{Ga}_{0.9} \mathrm{~N}: \mathrm{Mg}$} \\
\hline & $\omega_{\mathrm{E} 2}\left(\mathrm{~cm}^{-1}\right)$ & FWHM $_{\mathrm{E} 2}\left(\mathrm{~cm}^{-1}\right)$ & $\sigma_{\mathrm{a}}(\mathrm{MPa})$ & $\omega_{\mathrm{E} 2}\left(\mathrm{~cm}^{-1}\right)$ & FWHM $_{\mathrm{E} 2}\left(\mathrm{~cm}^{-1}\right)$ & $\sigma_{\mathrm{a}}(\mathrm{MPa})$ \\
\hline As-grown & $570.50 \pm 0.04$ & $6.15 \pm 0.10$ & - & $572.31 \pm 0.03$ & $5.48 \pm 0.15$ & - \\
\hline Implanted & - & - & - & - & - & - \\
\hline Ann.@900 ㄷ & $569.17 \pm 0.43$ & $7.01 \pm 1.44$ & 429 & $571.85 \pm 0.65$ & $9.05 \pm 1.41$ & 148 \\
\hline Ann. @ $1000{ }^{\circ} \mathrm{C}$ & $569.18 \pm 0.03$ & $5.27 \pm 0.08$ & 426 & $571.26 \pm 0.20$ & $5.90 \pm 0.75$ & 339 \\
\hline Ann. @ $1100{ }^{\circ} \mathrm{C}$ & $569.89 \pm 0.11$ & $6.74 \pm 0.33$ & 197 & $570.31 \pm 0.20$ & $6.86 \pm 0.84$ & 645 \\
\hline
\end{tabular}

$\omega_{E 2}$ frequency of $E_{2}$ (high) mode, $\sigma_{a}$ relative residual stress $(\mathrm{MPa})$ 
Fig. 4 Normalized SIMS profiles of $\mathrm{Mg}$ and $\mathrm{P}$ in GaN:Mg and AlGaN:Mg heterostructures
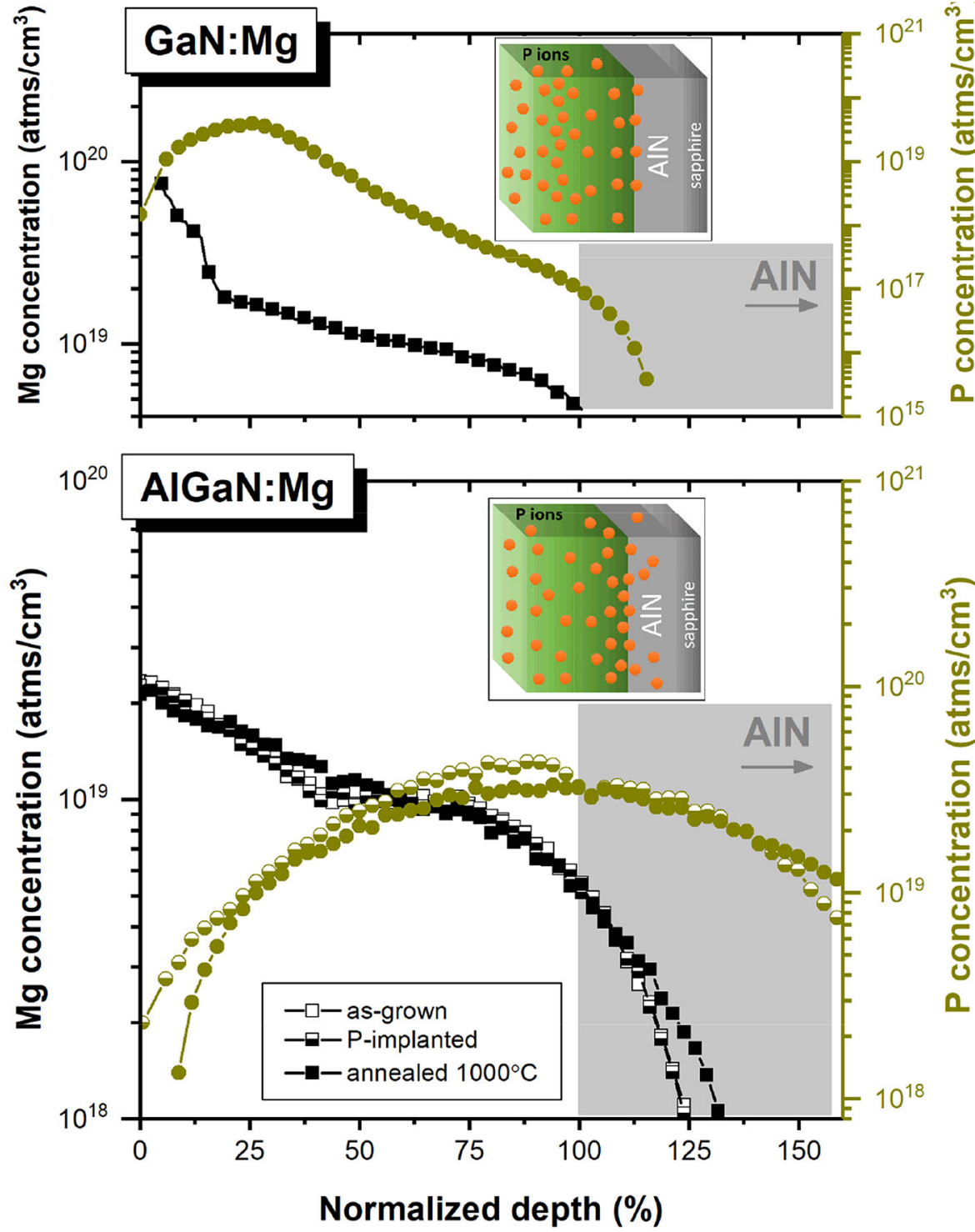

\subsection{Electrical characterization}

As mentioned in the introduction, adding $\mathrm{Mg}$ and $\mathrm{P}$ into $(\mathrm{Al}) \mathrm{GaN}$ heterostructure aimed at obtaining p-type conductivity. In the present studies, the Hall effect measurements were carried out for P-implanted and annealed (Al)GaN:Mg structures. The summary of electrical properties, compared with data from literature, is presented in Table 3. As a result of $\mathrm{P}$ implantation and annealing at $1000{ }^{\circ} \mathrm{C}$, a decrease in hole concentration from approximately $4 \times 10^{17} \mathrm{~cm}^{-3}$ to $3 \times 10^{11} \mathrm{~cm}^{-3}$ for GaN:Mg, and from approximately $2 \times 10^{17} \mathrm{~cm}^{-3}$ to $4 \times 10^{11} \mathrm{~cm}^{-3}$ for AlGaN:Mg was achieved. Interestingly, the observed trend in resistance is independent of composition or annealing temperature, while the hole concentration slightly increases with temperature.

In terms of the obtained electrical characteristics, Pearton [4] and Zolper [39] presented studies on electrical properties for $\mathrm{GaN}$ co-implantation with $\mathrm{Mg}$ and $\mathrm{P}$ ions. In their works, the effect of both the dose of implanted ions and the annealing temperature on the change of hole concentration was demonstrated. It was revealed that the higher the amount of dopant implanted into the structure, the more noticeable is the increase in hole concentration, varies from $10^{10}$ to $10^{12} \mathrm{~cm}^{-2}$ for a dose of co-implanted ions from $2 \times 10^{14}$ to $5 \times 10^{15} \mathrm{~cm}^{-2}$, respectively [4]. The annealing temperature affects not only 
Table 3 Electrical parameters for GaN:Mg and AlGaN:Mg heterostructures before and after P implantation and RTA treatment

\begin{tabular}{|c|c|c|c|c|c|}
\hline & & $\mathrm{P} / \mathrm{Mg}$ ratio & Hole concentration $\left(\mathrm{cm}^{-3}\right)$ & Resistivity $(\Omega \cdot \mathrm{cm})$ & Mobility $\left(\mathrm{cm}^{2} \mathrm{~V}^{-1} \mathrm{~s}\right)$ \\
\hline \multirow[t]{4}{*}{ This work } & GaN:Mg & 0.1 & $3.7 \times 10^{17}$ & 3.8 & 4 \\
\hline & $\mathrm{GaN}:(\mathrm{Mg} / \mathrm{P})$ & & $2.8 \times 10^{11}$ & $1.7 \times 10^{5}$ & 140 \\
\hline & $\mathrm{Al}_{0.1} \mathrm{Ga}_{0.9} \mathrm{~N}: \mathrm{Mg}$ & 0.1 & $1.9 \times 10^{17}$ & 4.4 & 8 \\
\hline & $\mathrm{Al}_{0.1} \mathrm{Ga}_{0.9} \mathrm{~N}:(\mathrm{Mg} / \mathrm{P})$ & & $4.4 \times 10^{11}$ & $5.0 \times 10^{5}$ & 28 \\
\hline \multirow[t]{6}{*}{ Literature } & Co-impl. GaN [4] & 1.0 & $9.5 \times 10^{11}$ & - & - \\
\hline & Co-impl. GaN [39] & 1.0 & $1.0 \times 10^{11}$ & - & - \\
\hline & $\mathrm{GaN}:(\mathrm{Mg}+\mathrm{P})[8]$ & 0.01 & $6.9 \times 10^{17}$ & - & 12 \\
\hline & $\mathrm{GaN}:(\mathrm{Mg}+\mathrm{P})[9]$ & 0.01 & $2.1 \times 10^{17}$ & 3.6 & 8.2 \\
\hline & $\mathrm{GaN}:(\mathrm{Mg}+\mathrm{P})[9]$ & 0.001 & $6.2 \times 10^{16}$ & 10.7 & 9.5 \\
\hline & Co-impl. $\mathrm{Al}_{0.12} \mathrm{Ga}_{0.88} \mathrm{~N}$ [17] & 1.0 & $2.3 \times 10^{11}$ & - & 95 \\
\hline
\end{tabular}

For comparison, the literature data for: (i) $\mathrm{GaN} \mathrm{Mg} / \mathrm{P}$ co-implanted (assigned as co-impl. GaN), (ii) GaN:Mg implanted with P (assigned as $G a N:(\mathrm{Mg}+\mathrm{P})$, and (iii) $\mathrm{AlGaN} \mathrm{Mg} / \mathrm{P}$ co-implanted (assigned as co-impl. $A l_{0.12} G a_{0.88} \mathrm{~N}$ ), is presented

the increase in concentration but also the type of conductivity. A sharp n-to-p conversion in conductivity type is observed after annealing at temperatures $>1000{ }^{\circ} \mathrm{C}$. Liu et al. showed also that annealing of P-implanted and $\mathrm{Mg}$-doped $\mathrm{GaN}$ at relatively high temperatures $\left(1200{ }^{\circ} \mathrm{C}\right)$ allows producing p-type conductivity with a hole concentration of $6.9 \times 10^{17} \mathrm{~cm}^{-3}$ and mobility of $12 \mathrm{~cm}^{2} \mathrm{~V}^{-1} \mathrm{~s}[8,9]$. To achieve such effect it is necessary to keep the $\mathrm{P} / \mathrm{Mg}$ ratio $=0.01$-reducing this ratio results in a deterioration of hole concentration (to $6.2 \times 10^{16} \mathrm{~cm}^{-3}$ for the ratio $\left.\mathrm{P} / \mathrm{Mg}=0.001\right)$. Probably the main reason for such a drastic deterioration of the electrical properties is an inadequate ratio of $\mathrm{P} / \mathrm{Mg}$, according to the work of Liu et al. [8, 9]. The SIMS results showed that for P-implanted GaN:Mg the ratio $\mathrm{P} / \mathrm{Mg}$ at the surface is about 0.1 , but deeper into the sample $(\sim 25 \%)$ this ratio significantly changes and is approximately 100. An analogous situation occurs for P-implanted AlGaN:Mg at the surface the ratio $\mathrm{P} / \mathrm{Mg} \sim 0.1$, while for standardized depth of $75 \%, \mathrm{P} / \mathrm{Mg}=2$. Thus, these results confirm that an appropriate ratio of $\mathrm{P}$ to $\mathrm{Mg}$ across the (Al)GaN layers is needed to achieve relatively good p-type conductivity $[8,9]$.

Importantly, a certain amount of $\mathrm{Mg}$ in the doped AlGaN structures is a key aspect influencing the electrical parameters. According to the Kozodoy et al. [40] and Zheng et al. works [41], the Mg concentration in $\mathrm{GaN}$ heterostructures has a crucial impact, but this value cannot be too high, because then the opposite effect occurs. After exceeding a certain $\mathrm{Mg}$ concentration $\left(10^{20} \mathrm{~cm}^{-3}\right)$, the system is over-doped with $\mathrm{Mg}$, which results in the formation of $\mathrm{Mg}$-rich precipitations on the surface, and significantly decreases of the electrical properties. Likely here, in the as-grown structures (GaN:Mg and $\mathrm{AlGaN}: \mathrm{Mg}$ ) too high $\mathrm{Mg}$ content was introduced, which did not harm the structure before implantation (with relatively good electrical characteristics), but the implantation and annealing revealed surface inhomogeneities in a shape of triangular pyramids (shown in the Electronic Supplementary Material on the electron microscopy micrographs). Therefore, with (Al)GaN heterostructures, it is necessary to control both the $\mathrm{P} / \mathrm{Mg}$ ratio and the $\mathrm{Mg}$ concentration across the whole layer to obtain the appropriate electrical parameters.

Concerning the ternary AlGaN structures, the only literature studies of $\mathrm{Mg}$ and $\mathrm{P}$ implantation and its effect on electrical parameters were shown by Polyakov et al. [17]. A high value of sheet resistivity (around $10^{12} \Omega / \mathrm{sq}$ ) was obtained for the as-implanted structures. Additionally, a long annealing $(>1 \mathrm{~h})$ at high temperature $\left(1140{ }^{\circ} \mathrm{C}\right)$ did not significantly reduce the resistivity of the layers. Besides, it was demonstrated in Si-implanted AlGaN heterostructures that after implantation and annealing the resistivity increased [42, 43]. In the other work, after protons implantation in AlGaN heterostructures the sheet resistivity was also very high $\left(10^{12} \Omega / \mathrm{sq}\right)$ but declined after annealing at $700{ }^{\circ} \mathrm{C}$ (to $10^{9} \Omega / \mathrm{sq}$ ) [17]. Up to now, there are no more reports on changes in electrical properties of P-implanted AlGaN:Mg. 


\section{Conclusion}

The detailed structural changes and elemental distribution of two epitaxially grown Mg-doped compounds: $\mathrm{GaN}$ and $\mathrm{Al}_{0.1} \mathrm{Ga}_{0.9} \mathrm{~N}$, implanted with $\mathrm{P}$ ions and further annealed are discussed. The HR-XRD, Raman, and SIMS measurements revealed that in terms of structural changes due to $\mathrm{P}$ implantation and thermal annealing these two compounds behave quite similar: (i) lattice mismatch and broadening of P-implanted ( $\mathrm{Al}) \mathrm{GaN}: \mathrm{Mg}$ structures were determine to be in the range of $0.55-0.60 \%$ and $31-42 \%$, respectively, (ii) $\mathrm{P}$ ion implantation-induced disorders in (Al)GaN:Mg are of similar nature to previously reported oxygen, and (iii) post-implantation annealing restores wurtzite arrangement though the treatment at temperatures higher than $1000{ }^{\circ} \mathrm{C}$ causes severe structural degradation. However, the diffusion length of implanted P ions is significantly higher in AlGaN:Mg than in GaN:Mg, possibly due to higher oxygen content in AlGaN. The post-growth annealing activates acceptor dopant, meaning that more $\mathrm{Mg}$ atoms are free to diffuse, increasing its average diffusion length. Thus, $\mathrm{P}$ atoms may behave like $\mathrm{Mg}$ and analogous to the $\mathrm{Mg}$ activation scenario, $\mathrm{P}$ diffusion length can be considerably larger in $\mathrm{Al}_{0.1} \mathrm{Ga}_{0.9} \mathrm{~N}$ than in GaN. Additionally, the $\mathrm{Mg}$ concentration in the as-grown ( $\mathrm{Al}) \mathrm{GaN}$ is crucial because too high $\mathrm{Mg}$ doping could be the reason for degradation of electrical properties of P-implanted (Al)GaN:Mg heterostructures. The presented studies demonstrate that despite the before pointed beneficial effects of $\mathrm{P}$ ions in acceptor activation and consequently p-type conductivity in (Al)GaN semiconductors, introduction of $\mathrm{P}$ has to be well controlled and possibly using other experimental approaches.

\section{Acknowledgements}

This work was supported by the National Science Centre (NCN) within the OPUS10 2015/19/B/ST7/ 02163 project and the National Center for Research and Development (NCBiR) within TECHMATSTRATEG (TECHMATSTRATEG1/346922/4/ NCBR/2017) project. Authors thank Grzegorz Gawlik for performing an ion implantation of (Al)GaN structures and Jacek Nizel for epitaxial growth.

\section{Funding}

This work was supported by the National Science Centre (NCN) within the OPUS10 2015/19/B/ST7/ 02163 Project and the National Centre for Research and Development (NCBiR) within TECHMATSTRATEG (TECHMATSTRATEG1/346922/4/ NCBR/2017) Project.

\section{Compliance with ethical standards}

Conflict of interest The authors declare that they have no conflict of interest.

Electronic supplementary material: The online version of this article (https://doi.org/10.1007/s108 54-020-04342-2) contains supplementary material, which is available to authorized users.

Open Access This article is licensed under a Creative Commons Attribution 4.0 International License, which permits use, sharing, adaptation, distribution and reproduction in any medium or format, as long as you give appropriate credit to the original author(s) and the source, provide a link to the Creative Commons licence, and indicate if changes were made. The images or other third party material in this article are included in the article's Creative Commons licence, unless indicated otherwise in a credit line to the material. If material is not included in the article's Creative Commons licence and your intended use is not permitted by statutory regulation or exceeds the permitted use, you will need to obtain permission directly from the copyright holder. To view a copy of this licence, visit http://creativecommons.org/licen ses $/$ by $/ 4.0 /$.

\section{References}

1. S.J. Pearton, C. Abernathy, M. Overberg, G. Thaler, A. Onstine, B. Gila, F. Ren, B. Lou, J. Kim, Mater. Today 5, 24-31 (2002)

2. K. Takeda, M. Iwaya, T. Takeuchi, S. Kamiyama, I. Akasaki, Jpn. J. Appl. Phys. 55, 5 (2016)

3. B.C. Chung, M. Gershenzon, J. Appl. Phys. 72, 651-659 (1992)

4. S.J. Pearton, C.B. Vartuli, J.C. Zolper, C. Yuan, R.A. Stall, Appl. Phys. Lett. 67, 1435 (1995) 
5. S.R. Aid, T. Uneme, N. Wakabayashi, K. Yamazaki, A. Uedono, S. Matsumoto, Phys. Status Solidi 1, 1700225 (2017)

6. S. Zlotnik, J. Sitek, K. Rosinski, P.P. Michalowski, J. Gaca, M. Wojcik, M. Rudzinski, Appl. Surf. Sci. 488, 688-695 (2019)

7. K.T. Liu, Y.K. Su, S.J. Chang, K. Onomitsu, Y. Horikoshi, Phys. Status Solidi C. 2697, 2693-2697 (2004)

8. K.T. Liu, Y.K. Su, R.W. Chuang, S.J. Chang, Y. Horikoshi, Microelectron. J. 37, 417-420 (2006)

9. K.T. Liu, S. Chang, S. Wu, Jpn. J. Appl. Phys. 48, 081003 (2009)

10. J.C. Zolper, J. Cryst. Growth 178, 157-167 (1997)

11. J. Karpiński, S. Porowski, J. Cryst. Growth 66, 11-20 (1984)

12. E.P. Carlson, D.W. Cunningham, I.C. Kizilyalli, ECS Trans. 86, 3-16 (2018)

13. T. Niwa, T. Fujii, Appl. Phys. Express 10, 091002 (2017)

14. J.D. Greenlee, B.N. Feigelson, T.J. Anderson, J.K. Hite, K.D. Hobart, F.J. Kub, ECS J. Solid State Sci. Technol. 4, P382P386 (2015)

15. M.J. Tadjer, B. Feigelson, J. Greenlee, J. Freitas, T. Anderson, J. Hite, L. Ruppalt, C. Eddy, K. Hobart, F. Kub, ECS J. Solid State Sci. Technol. 5, 124-127 (2016)

16. S.G. Sundaresan, M. Murthy, M.V. Rao, R.T. Holm, R.L. Henry, Semicond. Sci. Technol 22, 1151-1156 (2007)

17. A.Y. Polyakov, M. Shin, M. Skowronski, R.G. Wilson, D.W. Greve, S.J. Pearton, Solid State Electron. 41, 703-706 (1997)

18. R.M. Frazier, G.T. Thaler, C.R. Abernathy, S.J. Pearton, M.L. Nakarmi, K.B. Nam, J.Y. Lin, H.X. Jiang, J. Kelly, R. Rairigh, A.F. Hebard, J.M. Zavada, R.G. Wilosn, J. Appl. Phys. 94, 4956-4960 (2003)

19. A.Y. Polyakov, N.B. Smirnov, A.V. Govorkov, S.J. Pearton, R.M. Frazier, G.T. Thaler, C.R. Abernathy, J.M. Zavada, Semicond. Sci. Technol. 19, 1169-1173 (2004)

20. Y. Nakano, O. Fujishima, T. Kachi, K. Abe, O. Eryu, K. Nakashima, T. Jimbo, J. Electrochem. Soc. 151, 801-804 (2004)

21. Y. Irokawa, O. Fujishima, T. Kachi, S.J. Pearton, F. Ren, Appl. Phys. Lett. 86, 1-3 (2005)

22. E.A. Moore, Y.K. Yeo, M.Y. Ryu, Curr. Appl. Phys. 12, 123-128 (2012)

23. K. Nomoto, Y. Toyoda, M. Satoh, T. Inada, T. Nakamura, Nucl. Instrum. Methods Phys. Res. Sect. B 272, 125-127 (2012)

24. M.Y.I. Ryu, Y.K. Yeo, M.A. Marciniak, T.W. Zens, E.A. Moore, R.L. Hengehold, T.D. Streiner, J. Electron. Mater. 35, 647-653 (2006)
25. Y. Wang, T. Bai, C. Li, M.J. Tadjer, T.J. Anderson, J.K. Hite, M.A. Mastro, C.R. Eddy, K.D. Hobart, B.N. Feigelson, M.S. Goorsky, ECS J. Solid State SC. 8, 70-76 (2019)

26. M. Sumiya, K. Fukuda, H. Iwai, T. Yamaguchi, T. Onuma, T. Honda, AIP Adv. 8, 115225 (2018)

27. M. Kuball, Surf. Interface Anal. 31, 987-999 (2001)

28. M. Kadleíková, J. Breza, M. Veselý, Microelectron. J. 32, 955-958 (2001)

29. A. Majid, J.J. Zhu, U.A. Rana, S. Ud-Din Khan, RSC Adv. 6, 73589-73594 (2016)

30. A. Pandey, R. Raman, S. Dalal, D. Kaur, A.K. Kapoor, Mater. Sci. Semicond. Process. 107, 104833 (2020)

31. M. Katsikini, K. Papagelis, E.C. Paloura, S. Ves, J. Appl. Phys. 94, 4389-4394 (2003)

32. X. Gao, C. Liu, D. Tao, Y. Zeng, J. Alloys Compd. 644, 694-697 (2015)

33. A. Macková, P. Malinsky, A. Jagerova, Z. Sofer, K. Klimova, D. Sedmidubsky, M. Pristovsek, M. Mikulics, J. Lorincik, R. Bottger, S. Akhmadaliev, Thin Solid Films 638, 63-72 (2017)

34. D. Pastor, J. Ibáñez, R. Cuscó, L. Artús, G. González-Díaz, E. Calleja, Semicond. Sci. Technol. 22, 70-73 (2007)

35. W.H. Sun, S.J. Chua, L.S. Wang, X.H. Zhang, J. Appl. Phys. 91, 4917-4921 (2002)

36. S. Tripathy, S.J. Chua, P. Chen, Z.L. Miao, J. Appl. Phys. 92, 3503-3510 (2002)

37. S. Choi, E. Heller, D. Dorsey, R. Vetury, S. Graham, J. Appl. Phys. 113, 93510 (2013)

38. P.P. Michałowski, S. Złotnik, J. Sitek, K. Rosiński, M. Rudziński, Phys. Chem. Chem. Phys. 20, 13890-13895 (2018)

39. J.C. Zolper, M.H. Crawford, J.S. Williams, H.H. Tan, R.A. Stall, Nucl. Instrum. Methods Phys. Res. Sect. B 127-128, 467-470 (1997)

40. P. Kozodoy, H. Xing, S.P. DenBaars, U.K. Mishra, J. Appl. Phys. 87, 1832-1835 (2000)

41. T. Zheng, W. Lin, D. Cai, Y. Weihuang, W. Jiang, H. Chen, J. Li, S. Li, J. Kang, Nanoscale Res. Lett. 9, 40 (2014)

42. F. Recht, L. McCarthy, S. Rajan, A. Chakraborty, C. Poblenz, A. Corrion, J.S. Speck, U.K. Mishra, IEEE Electron Device Lett. 27, 205-207 (2006)

43. K.A. Jones, T.P. Chow, M. Wraback, M. Shatalov, Z. Sitar, F. Shahedipour, K. Udwary, G.S. Tompa, J. Mater. Sci. 50, 3267-3307 (2015)

Publisher's Note Springer Nature remains neutral with regard to jurisdictional claims in published maps and institutional affiliations. 